\title{
Artificial Intelligence in Pre-operative Assessment of Patients in Colorectal Surgery
}

\section{Kolorektal Cerrahide Hastaların Ameliyat Öncesi Değerlendirilmesinde Yapay Zeka}

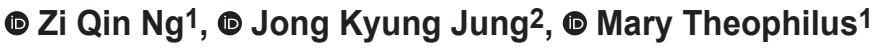 \\ 1 St John of God Midland Hospital, Clinic of General Surgery, Australia \\ 2Health Data Administrator Analytics and Data Science Ramsay Health Care, Australia
}

\section{HIIIII| ABSTRACT}

The pre-operative assessment of patients in colorectal surgery has become an important focus in the last decade to optimize the patients and reduce the post-operative morbidity and mortality. Various scoring systems have been developed in the past but are usually limited by its use in real world clinical setting. Artificial intelligence (AI) in medicine is increasingly evaluated for its use for diagnostic and prognostic value. This is coincided with the development of big data where electronic health records are increasingly used in hospitals. AI has the potential to assist in the pre-operative risk assessment of patient from all aspects by composing the readily available data comprising of basic demographics, biochemistry, and radiology results. In this review, we discuss about the potential use of AI in pre-operative assessment of patients in colorectal surgery, the current issues and limitations and future development.

Keywords: AI, pre-operative, assessment, data, colorectal

\section{||||||||||| ÖZ}

Kolorektal cerrahide hastaların preoperatif değerlendirilmesi, hastaları optimize etmek ve postoperatif morbidite ve mortaliteyi azaltmak için son on yılda önemli bir odak haline gelmiştir. Geçmişte çeşitli puanlama sistemleri geliştirilmiştir, ancak genellikle bunların gerçek dünya klinik uygulamasında kullanımı sınırlı kalmıştır. Tıpta yapay zekanın (YZ) tanısal ve prognostik açısından kullanımı giderek daha fazla test edilmektedir. Bu, elektronik sağlık kayıtlarının hastanelerde giderek daha fazla kullanıldı̆̆ı büyük verinin gelişmesiyle aynı zamana denk gelmektedir. YZ, temel demografik veriler, biyokimya ve radyoloji sonuçlarından oluşan hazır verileri oluşturarak hastanın ameliyat öncesi risk değerlendirmesine her yönden yardımcı olma potansiyeline sahiptir. Bu derlemede, kolorektal cerrahide hastaların ameliyat öncesi değerlendirilmesinde YZ’nin potansiyel kullanımını, güncel sorunları, sınırlamaları ve gelecekteki gelişmeleri tartışacağız.

Anahtar Kelimeler: YZ, ameliyat öncesi, değerlendirme, veri, kolorektal

\section{Introduction}

Colorectal surgery forms a significant core of general surgery, in both elective and emergency settings. As the life expectancy increases, the global population will be further burdened with chronic diseases expectedly. Similarly, the incidence of other conditions such as diverticular disease and colorectal malignancy are predicted to increase. ${ }^{1,2}$ With an increasing older population, clinicians will face a significant dilemma of weighing the risks and benefits of surgical intervention of increasing complexity against underlying comorbidities.

There has been long-term optimism that artificial intelligence (AI) will be able to address various areas of deficiency in medicine. AI represents an umbrella term of increasing models of machine learning. AI is believed to mimic human cognitive abilities including "learning" and "problem solving". Models include Bayesian inference, decision trees,

Address for Correspondence/Yazışma Adresi: Zi Qin Ng, MD, 
linear discriminants, support vector machines, logistic regression and artificial neural networks (ANN). ${ }^{3,4}$

The recent surge in interest in AI spans various medical specialties and coincides with the popularisation of the concept of "big data" ${ }^{5,6}$ Traditionally, this has involved large and complex data sets that cannot be easily analysed. More recently, however, big data has been described using the 5 Vs: volume, velocity, variety, variability and value. Hospital systems, meanwhile, are constantly being improved as evidenced by the progressive widespread use of electronic health records. These data, whilst readily available, are often untapped but can be utilised in various AI models. For example, in the field of gastroenterology, the prospectively collected database of an enormous number of digital images of polyps is currently used for machine learning so that the AI model can assist in further enhanced detection and discrimination of polyps in colonoscopy. ${ }^{3}$

In this review, the discussion will focus on data that are readily available in our daily clinical practice and the potential use of $\mathrm{AI}$ in integrating these data into meaningful composite data to guide pre-operative management in colorectal surgery.

\section{How does AI Work?}

Traditionally, machine learning was the most common form of AI where mathematical algorithm is built upon a given set of data and provides an output (prediction or prognostication). Deep learning is a newer form of machine learning, which has shown its promise through both ANN and convolutional neural networks. ANN can provide remarkable performance in diagnostic and prognostic prediction through appropriate learning process and adjusting the value of the connection weight to optimise the best result. The availability of big data has helped overcome its limitations of overfitting.

Five main stages are employed in developing and deploying machine learning models (Figure 1):

1. Ingestion: Identifying data sources and collecting data in batch, real time or streaming.

2. Store: Data need to be stored and joined. Metadata can exist on premise and/or in the cloud.

3. Train: Using various methods (e.g. AutoML, Python, R and SSML), machine learning models can be developed.

4. Deploy: Models needs to be packaged and registered for deployment.

5. Consume: Models can be consumed in various ways depending on the deployment pathway. For example, by using RESTFUL APIs, models can be integrated in new or existing applications and reports.

\section{What is Already Available and What Else do We Need?}

Big data are already present in our daily clinical practice, be it in written or electronic form. Conventional research methods rely on manual search of health records, which can be time consuming, prone to errors and labour intensive. For prospective databases to be successful, they require dedicated research personnel and the commitment of all clinicians to ensure data adequacy and integrity. The lack of participation stems from common themes, such as involvement is "time consuming", "too cumbersome" and "irrelevant to their personal practice". Although many hospitals are moving towards using electronic health records, which may address some of these issues, a lack of uniformity and governance may hinder other aspects.

During the hospital admission, patient's demographics such as age, gender, nationality, race and occupation are recorded. Clinical details are also collected-symptoms and clinical signs (such as heart rate, blood pressure, respiratory rate, oxygen saturation and temperature and abdominal examination findings) that are part of usual documentation. Biochemistry results such as haemoglobin, platelet count, white cell count, C-reactive protein, renal function, liver function, iron studies and tumour markers are easily accessible. Imaging results including computed tomography (CT), magnetic resonance imaging and/or positron emission tomography with endoscopic results are the current standard of care in the workup of colorectal disease. Hence, we need an automatic integration system for these data to be inputted into AI for various purposes as explained in the following sections.

\section{Al in Pre-operative Scoring Systems}

Various scores/classifications have been developed in the past but frequently overlooked in the clinical setting because of impracticality. ${ }^{7,8}$ For example, the POSSUM score consists of 18 parameters to estimate the risk of morbidity and mortality in patients undergoing general surgery. ${ }^{9}$ Although most of the parameters are relevant, often one size does not fit all. They are mostly utilised for standardisation in research protocols. Hence, most clinicians often based the fitness of patients for surgery on their bedside clinical judgement, which can be affected by the level of experience. The American Society of Anaesthesiologist score, though universal and easy to use to gauge the fitness of patients prior to both elective and emergency surgery, cannot be used for prognostication. ${ }^{9}$ More recently, the National Emergency Laparotomy Audit that originated from the UK is increasingly used to provide a calculated mortality risk in emergency surgery. Although the 30-day mortality did not differ between the pre-use and post-use period, a 
significant decrease was found in unplanned admissions to the intensive care unit. ${ }^{10}$ Likewise, some of the parameters are not transferable to the elective setting or tailored to certain emergency procedures.

The ideal pre-operative scoring system should be applicable to both elective and emergency settings. With the availability of big data, different variables can be fed into the AI for machine learning to create a new score and independently and continuously self-validate its sensitivity and specificity. Having a unique score for individual procedures may be even possible!

\section{Al in Pre-operative Imaging and Decision Making}

The pre-operative use of modern imaging techniques for diagnosis, prognostication and surgical planning is increasing. Some studies have shown that the use of AI in this area can demonstrate a reliably high degree of sensitivity and specificity in diagnosis. ${ }^{11}$

Despite improved imaging techniques, detection of certain "lesions" in staging CT scans still pose a dilemma in its significance. For instance, it is not uncommon to detect small pulmonary nodules for which consensus on their identity and significance may not be reached even in the setting of a multidisciplinary meeting. Given that their significance can alter the management of the patient, the use of AI may help differentiate benign from malignant lesions, as shown in a study where AI has a higher sensitivity and specificity in the detection of lung cancer nodules. ${ }^{12}$

AI has the capability to reconstruct the area of interest from two-dimensional data obtained from imaging and endoscopic findings and project them to a three-dimensional structure to clearly display the tumour in relation to the surrounding vital structures for pre-operative surgical planning. ${ }^{13}$ This is extremely useful in anticipated difficult cases such as local tumour invasion where pre-emptive involvement of urological and vascular expertise and management can minimise morbidity.

\section{Al in Predicting Post-operative Outcomes}

Post-operative complications often lead to unplanned return to theatre, unplanned critical care need or prolonged hospital stay and readmissions. Some of the most undesired complications in colorectal surgery are anastomotic leak, wound infection, pneumonia and thromboembolic events. Tools to evaluate individual patient risk of complications can help counsel patients and determine most feasible options that minimise risk. ${ }^{4}$ Radiological investigations have unused big data that could be interpreted by AI for risk assessment of these potential morbidities. Firstly, the role of aorto-iliac classification index on CT scan has been evaluated to correlate with the risk of anastomotic leak in colorectal surgery. ${ }^{14}$ This is relevant in the older population that is usually burdened with chronic atherosclerotic disease.

\section{Machine Learning Life Cycle}

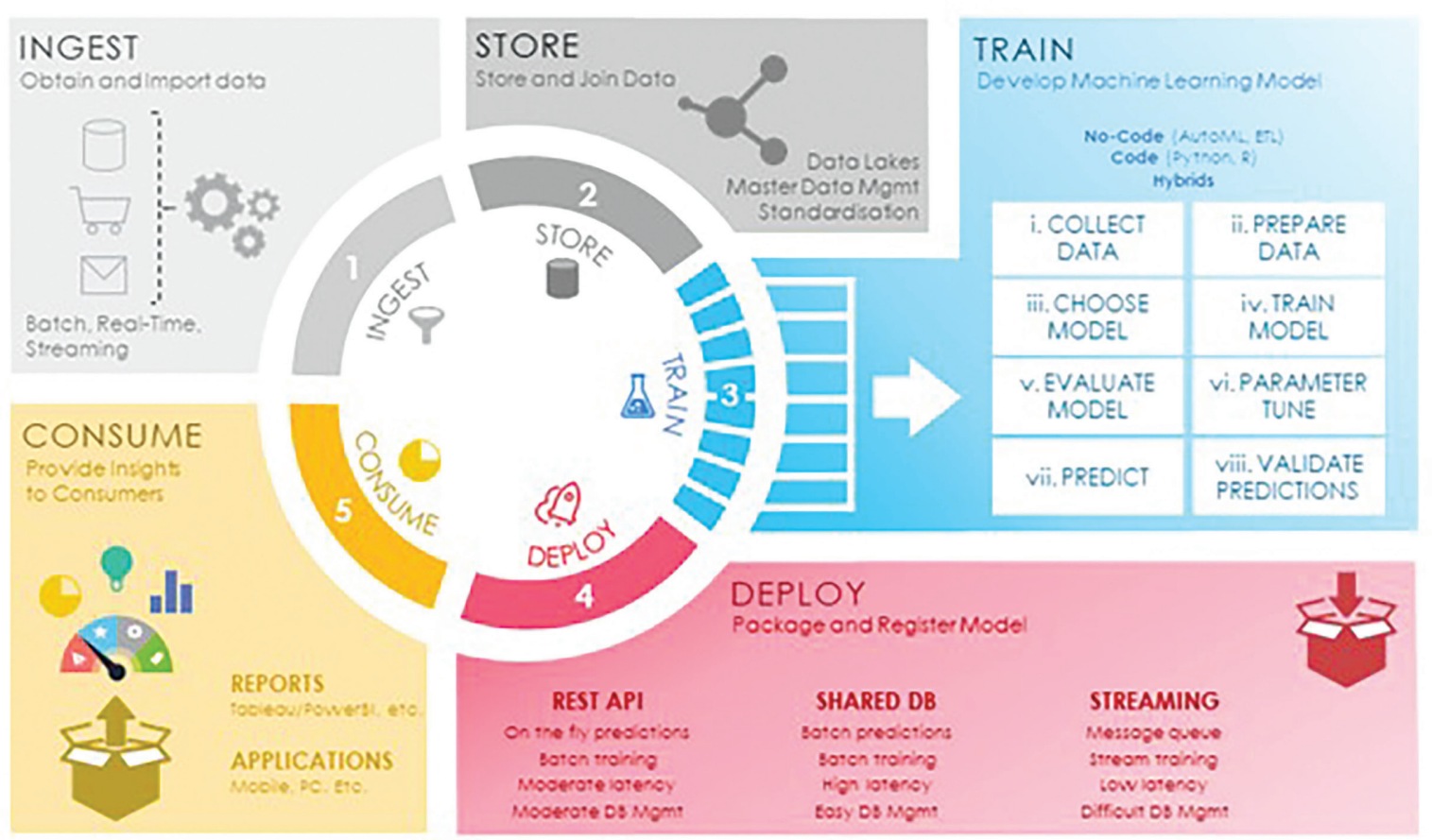

Figure 1. A graphic illustration of the five stages of machine learning life cycle 
Secondly, on the CT scan, the radiological quantitative measurement of visceral adiposity has been reported to be a far more accurate surrogate marker for complications than body mass index. ${ }^{15}$ The association of body mass index with surgical outcomes, especially in the emergency setting, has been paradoxical. Benjamin et al. ${ }^{16}$ showed that underweight and class III obesity were associated with increased complications, whereas mild obesity was protective. With the increasing obesity endemic, this will help further stratify patients with high-risk status and optimise them pre-operatively through weight reduction. Thirdly, the measurement of psoas muscle area as a marker for sarcopenia has been shown to be an independent prognostic factor for post-operative complication..$^{17,18}$

When considered together with other underlying factors, AI has the capability to simplify this and provide an objective "final score" that can be used to inform shared decision making.

\section{How do We Use It? Comprehensive Assessment by Al and Practical Clinical Utility}

AI was envisaged to produce a comprehensive risk assessment encompassing the results of pre-operative scoring and the aforementioned imaging findings to identify patients who have high-risk status and frailty who would benefit from a period of prehabilitation in terms of nutrition, muscle strength and psychological training. ${ }^{19}$

We illustrate in the following an example of the clinical use of AI (Figure 2). By using non-clinical data from the Patient Administration Systems and a simple machine learning stack (e.g. SQL, Jupyter Lab, Sci-Kit Learn, Flask and HTML5), a proof of concept such as below can be developed and locally hosted to assess the risk of inpatient mortality.

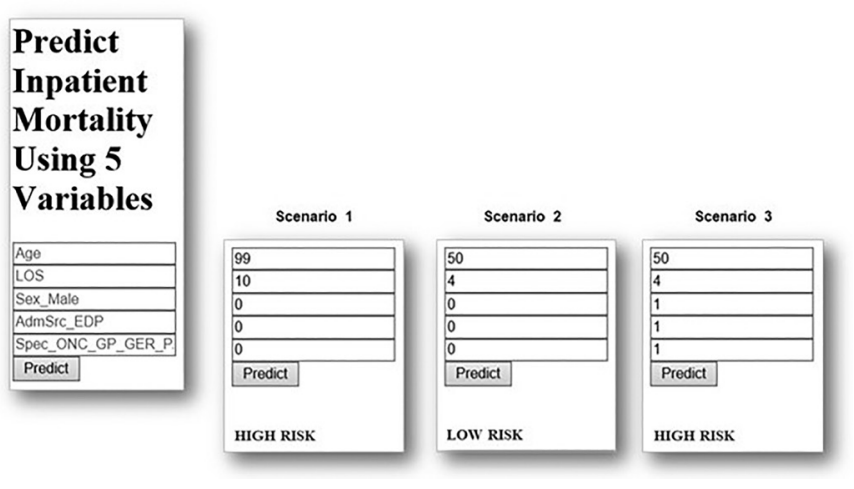

Figure 2. An example of using AI with five simple variables to predict inpatient mortality risk

AI: Artificial intelligence
To simplify the use of this model, only five features were selected after analysis of over 30 variables:

1. Age-patient's age in years as an integer

2. Length of stay-expected or actual length of stay in days as an integer

3. Sex- "1" for male; "0" for female

4. Admitted by emergency department-was the patient admitted from emergency department? "1" for yes; "0" for no

5. Specialty of admitting doctor- "1" if any of the following specialty: general surgery, oncology, general practice, geriatrics, palliative, cardiology

Remember that the risk assessment from AI does not consider the patient and family wishes. Ultimately, the outcome produced by AI should be used as an adjunct to guide decision rather than to replace the open discussion between all parties.

\section{Other Uses: Al for Colorectal Diseases for Management}

The global network of connection has enabled multinational collaborations and the establishment of national registries. AI can create and cross-link all registries to create an even "bigger" set of big data. This has the benefits of recruiting a large number of patients in a short period of time for the following purposes:

(i) Monitoring of effectiveness and side effects of a new neoadjuvant or adjuvant therapy. For instance, long-term oncological data in patients who are placed on a "watch and wait" strategy for locally advanced rectal cancer following complete clinical response is still unknown. ${ }^{20}$ Another new strategy where total neoadjuvant chemotherapy is employed for rectal cancer is an area of interest. ${ }^{21}$

(ii) Monitoring of complications and long-term value of a new procedure. For example, the recent interest in complete mesocolic excision and/or central vascular ligation for colonic cancers has sparked a debate on whether it should be undertaken owing to its potential serious complications and contradictory evidence on its benefits long-term oncologic outcome. This can be addressed by creation of a multinational registry through AI. ${ }^{22}$

(iii) Study of rare colorectal diseases such as gastrointestinal stromal tumour, ${ }^{23}$ primary colonic lymphoma ${ }^{24}$ and neuroendocrine tumour. ${ }^{25}$ The clinical presentation, risk factors and clinical outcomes will enhance better understanding of the tumour biology and advise future management strategies.

\section{Potential Issues with AI}

Despite the promise that AI offers, the clinician must be aware of its current strengths and limitations. At present, AI consists mainly of supervised learning through input of 
data. The quality of big data still relies on the type of data and its method of collection. The systems are not universally linked, and extraction of important outcomes is difficult. For example, the Bi-National Colorectal Cancer Audit is not mandatory for all colorectal cancer surgery; therefore, voluntary contribution of data will not accurately reflect practice across these countries. ${ }^{26}$ Data privacy legislation that varies between jurisdictions and states is also a hindrance to data sharing without individual consents. For the future, appropriate storage of big data should instil confidence in protecting confidentiality and privacy of patients. State and national health departments should collaborate to obtain the consent through an "opt-out" policy.

We hoped that current limitations can be overcome so that the current phase of supervised AI can be propelled into unsupervised learning and finally the establishment of a "final score". AI should be reinforced with continuous learning using prospective data that share the universal language to improve sensitivity and specificity and provide real-time decision. This will hopefully address the potential issues of overfitting and spectrum bias with current AI.

\section{Conclusion}

The current development of AI promises to bring about an exciting paradigm shift in clinical management, especially in the pre-operative assessment of patients in the field of colorectal surgery. The future AI is anticipated to be integrated to routine clinical care to reduce the postoperative morbidity and mortality.

Peer-review: Externally and internally peer reviewed.

\section{Authorship Contributions}

Surgical and Medical Practices: Z.Q.N., J.K.J., M.T., Concept: Z.Q.N., J.K.J., M.T., Design: Z.Q.N., J.K.J., M.T., Data Collection or Processing: Z.Q.N., J.K.J., M.T., Analysis or Interpretation: Z.Q.N., J.K.J., M.T., Literature Search: Z.Q.N., J.K.J, M.T., Writing: Z.Q.N., J.K.J., M.T.

Conflict of Interest: No conflict of interest was declared by the authors.

Financial Disclosure: The authors declared that this study received no financial support.

\section{References}

1. Tursi A, Brandimarte G, Di Mario F, Lanas A, Scarpignato C, Bafutto M, Barbara G, Bassotti G, Binda GA, Biondi A, Biondo S, Cambie G, Cassieri C, Crucitti A, Dumitrascu DL, Elisei W, Escalante R, Herszenyi L, Kruis W, Kupcinskas J, Lahat A, Lecca PG, Maconi G, Malfertheiner P, Mazzari A, Mearin F, Milosavljevic T, Nardone G, Chavez De Oliveira E, Papa A, Papagrigoriadis S, Pera M, Persiani R, Picchio M, Regula J, Stimac D, Stollman N, Strate LL, Violi A, Walker MM. international consensus on diverticulosis and diverticular disease. statements from the $3 \mathrm{rd}$ international symposium on diverticular disease. J Gastrointestin Liver Dis 2019;28(Suppl 4):57-66
2. Favoriti P, Carbone G, Greco M, Pirozzi F, Pirozzi RE, Corcione F. Worldwide burden of colorectal cancer: a review. Updates Surg 2016;68:711 .

3. Yang YJ, Bang CS. Application of artificial intelligence in gastroenterology. World J Gastroenterol 2019;25:1666-1683.

4. Francis NK, Luther A, Salib E, Allanby L, Messenger D, Allison AS, Smart NJ, Ockrim JB. The use of artificial neural networks to predict delayed discharge and readmission in enhanced recovery following laparoscopic colorectal cancer surgery. Tech Coloproctol 2015;19:419-428.

5. Cobb AN, Benjamin AJ, Huang ES, Kuo PC. Big data: More than big data sets. Surgery 2018;164:640-642.

6. Willems SM, Abeln S, Feenstra KA, de Bree R, van der Poel EF, Baatenburg de Jong RJ, Heringa J, van den Brekel MWM. The potential use of big data in oncology. Oral Oncol 2019;98:8-12

7. Thahir A, Pinto-Lopes R, Madenlidou S, Daby L, Halahakoon C. Mortality risk scoring in emergency general surgery: are we using the best tool? J Perioper Pract 2020;31:153-158.

8. Hunter Emergency Laparotomy Collaborator G, Hunter Emergency Laparotomy Collaborator G. High-Risk Emergency Laparotomy in Australia: Comparing NELA, P-POSSUM, and ACS-NSQIP Calculators. J Surg Res 2020;246:300-304.

9. Leung E, McArdle K, Wong LS. Risk-adjusted scoring systems in colorectal surgery. Int J Surg 2011;9:130-135

10. Mak M, Hakeem AR, Chitre V. Pre-NELA vs NELA - has anything changed, or is it just an audit exercise? Ann R Coll Surg Engl 2016;98:554-559.

11. Ding L, Liu GW, Zhao BC, Zhou YP, Li S, Zhang ZD, Guo YT, Li AQ, Lu Y, Yao HW, Yuan WT, Wang GY, Zhang DL, Wang L. Artificial intelligence system of faster region-based convolutional neural network surpassing senior radiologists in evaluation of metastatic lymph nodes of rectal cancer. Chin Med J (Engl) 2019;132:379-387.

12. Schwyzer M, Martini K, Benz DC, Burger IA, Ferraro DA, Kudura K, Treyer V, von Schulthess GK, Kaufmann PA, Huellner MW, Messerli M. Artificial intelligence for detecting small FDG-positive lung nodules in digital PET/ CT: impact of image reconstructions on diagnostic performance. Eur Radiol 2020;30:2031-2040

13. Kim HJ, Choi GS, Park JS, Park SY, Cho SH, Seo AN, Yoon GS. S122: impact of fluorescence and 3D images to completeness of lateral pelvic node dissection. Surg Endosc 2020;34:469-476.

14. Knight KA, Horgan PG, McMillan DC, Roxburgh CSD, Park JH. The relationship between aortic calcification and anastomotic leak following gastrointestinal resection: A systematic review. Int J Surg 2020;73:42-49.

15. Ng ZQ, Wijesuriya R, Misur P, Tan JH, Moe KS, Theophilus M. The role of quantitative radiological measures of visceral adiposity in diverticulitis. Surg Endosc 2020;35:636-643.

16. Benjamin ER, Dilektasli E, Haltmeier T, Beale E, Inaba K, Demetriades D. The effects of body mass index on complications and mortality after emergency abdominal operations: the obesity paradox. Am J Surg 2017;214:899-903

17. Hanaoka M, Yasuno M, Ishiguro M, Yamauchi S, Kikuchi A, Tokura M, Ishikawa T, Nakatani E, Uetake H. Morphologic change of the psoas muscle as a surrogate marker of sarcopenia and predictor of complications after colorectal cancer surgery. Int J Colorectal Dis 2017;32:847-856.

18. Herrod PJJ, Boyd-Carson H, Doleman B, Trotter J, Schlichtemeier S, Sathanapally G, Somerville J, Williams JP, Lund JN. Quick and simple; psoas density measurement is an independent predictor of anastomotic leak and other complications after colorectal resection. Tech Coloproctol 2019;23:129-134

19. Bolshinsky V, Li MH, Ismail H, Burbury K, Riedel B, Heriot A. Multimodal prehabilitation programs as a bundle of care in gastrointestinal cancer surgery: a systematic review. Dis Colon Rectum 2018;61:124-138. 
$\mathrm{Ng}$ et al.

AI in Work-up of Colorectal Surgery

20. Dossa F, Chesney TR, Acuna SA, Baxter NN. A watch-and-wait approach for locally advanced rectal cancer after a clinical complete response following neoadjuvant chemoradiation: a systematic review and metaanalysis. Lancet Gastroenterol Hepatol 2017;2:501-513.

21. Kasi A, Abbasi S, Handa S, Al-Rajabi R, Saeed A, Baranda J, Sun W. Total neoadjuvant therapy vs standard therapy in locally advanced rectal cancer: a systematic review and meta-analysis. JAMA Netw Open 2020;3:e2030097. doi: 10.1001/jamanetworkopen.2020.30097.

22. Wang C, Gao Z, Shen K, Shen Z, Jiang K, Liang B, Yin M, Yang X, Wang $S$, Ye Y. Safety, quality and effect of complete mesocolic excision vs noncomplete mesocolic excision in patients with colon cancer: a systemic review and meta-analysis. Colorectal Dis 2017;19:962-972

23. NS IJ, Mohammadi M, Tzanis D, Gelderblom H, Fiore M, Fumagalli E, Rutkowski P, Bylina E, Zavrakidis I, Steeghs N, Bonenkamp HJ, van Etten
B, Grunhagen DJ, Rasheed S, Tekkis P, Honore C, van Houdt W, van der Hage J, Bonvalot S, Schrage Y, Smith M. Quality of treatment and surgical approach for rectal gastrointestinal stromal tumour (GIST) in a large European cohort. Eur J Surg Oncol 2020;46:1124-1130.

24. Skube SJ, Arsoniadis EG, Sulciner ML, Gilles SR, Gaertner WB, Madoff RD, Melton GB, Peterson BA, Kwaan MR. Colorectal Lymphoma: A Contemporary Case Series. Dis Colon Rectum 2019;62:694-702.

25. Ramage JK, Valle JW, Nieveen van Dijkum EJM, Sundin A, Pascher A, Couvelard A, Kloeppel G, the EMABP, Participants EMAB. Colorectal Neuroendocrine Neoplasms: Areas of Unmet Need. Neuroendocrinology 2019;108:45-53

26. Hunter RA, Moore J, Committee BO. Evolution of the Bi-National Colorectal Cancer Audit: history, governance and future directions. ANZ J Surg 2016;86:431-432. 